Amenta, Marelli and Crepaldi, in press. To appear in Journal of Experimental Psychology: Learning, Memory and Cognition.

Running head: EARLY MORPHOLOGICAL PROCESSING IN SENTENCE READING

The fruitless effort of growing a fruitless tree:

Early morpho-orthographic and morpho-semantic effects in sentence reading.

\author{
Simona Amenta ${ }^{1}$, Marco Marelli ${ }^{2}$, Davide Crepaldi ${ }^{1,3}$ \\ ${ }^{1}$ Department of Psychology, University of Milano-Bicocca, Milano, Italy \\ ${ }^{2}$ Center for Mind/Brain Sciences, University of Trento, Rovereto, Italy \\ ${ }^{3}$ Milan Center for Neuroscience (NeuroMi), Milano, Italy
}

Author Note

Simona Amenta, Department of Psychology, University of Milano-Bicocca; Marco Marelli, Centre for Mind/Brain Sciences, University of Trento; Davide Crepaldi, Department of Psychology, University of Milano-Bicocca and Milan Center for Neuroscience.

Authors' contributions are as follows: Marco and Simona conceived the experiment; Simona created the stimuli, with contribution from Marco and Davide; Simona collected the data; Marco and Simona analyzed the data; Simona, Marco and Davide drafted the article. We thank Sara Ruggeri for her help in creating the stimuli set and collecting the data. This research was in part supported by a "FIRB-Futuro in Ricerca" grant from the Italian Ministry of Education, University and Research awarded to Davide Crepaldi. 
Amenta, Marelli and Crepaldi, in press. To appear in Journal of Experimental Psychology: Learning, Memory and Cognition.

Correspondence concerning this article should be addressed to Simona Amenta, Department of Psychology, University of Milano-Bicocca, P.zza dell'Ateneo Nuovo 1, 20123, Milan, Italy; phone number: $\equiv 39-02-64483736$ (direct); fax number: +39-02-64483706 (departmental); email: simona.amenta@unimib.it.

\begin{abstract}
In this eye-tracking study, we investigated how semantics inform morphological analysis at the early stages of visual word identification in sentence reading. We exploited a feature of several derived Italian words, that is, that they can be read in a "morphologically transparent" way or in a "morphologically opaque" way according to the sentence context to which they belong. This way, each target word was embedded in a sentence eliciting either its transparent or opaque interpretation. We analyzed whether the effect of stem frequency changes according to whether the (very same) word is read as a genuine derivation (transparent context) vs. as a pseudo-derived word (opaque context). Analysis of the first fixation durations revealed a stem-word frequency effect in both opaque and transparent contexts, thus showing that stems were accessed whether or not they contributed to word meaning, that is, word decomposition is indeed blind to semantics. However, while the stem-word frequency effect was facilitatory in the transparent context, it was inhibitory in the opaque context, thus showing an early involvement of semantic representations. This pattern of data is revealed by words with short suffixes. These results indicate that derived and pseudo-derived words are segmented into their constituent morphemes also in natural reading; however, this blindto-semantics process activates morpheme representations that are semantically connoted.
\end{abstract}

Keywords: Morphological processing, semantic transparency, sentence reading, eye-tracking, frequency effects. 
Amenta, Marelli and Crepaldi, in press. To appear in Journal of Experimental Psychology: Learning, Memory and Cognition.

\section{The fruitless effort of growing a fruitless tree: Early morpho-orthographic and morpho-semantic effects in sentence reading.}

Most words used in everyday life have a complex internal structure, that is, they can be broken down into smaller units that provide a well-identified contribution to their meaning (e.g., heal-er, bed-room). These smaller units, called morphemes, combine productively, which is key for the incredible communicative power of human languages and provides room for their evolution over time through the creation of new words (e.g., bioweapon, guesstimate, flexsecurity, etc.; Algeo, 1991).

Psycholinguists demonstrated nearly 40 years ago that the visual word identification system captures word internal structure (e.g., Taft \& Forster, 1975). However, there are still key aspects of how this happens that are far from being settled.

One of these aspects concerns how semantics informs morphological analysis. Longtin, Segui and Halle (2003), and Rastle, Davis and New (2004), among others, carried out masked priming studies showing equivalent facilitation in pairs like dealer-DEAL, where primes and targets entertain a genuine morphological relationship, and pairs like corner-CORN, where instead primes can be segmented morphologically $(c o r n+e r)$, but are completely unrelated in meaning to their pseudo-stem (a corner is not someone who "corns"). On the basis of these data, some scholars argued that semantics does not inform morphological segmentation, at least early in processing (Crepaldi, Rastle, Coltheart \& Nickels, 2010; Rastle \& Davis, 2008). There are studies, however, where a significant difference between transparent and opaque pairs was reported (Diependaele, Sandra \& Grainger, 2005; Feldman, O’Connor \& Moscoso del Prado Martín, 2009; Feldman, Kostić, Gvozdenović, O’Connor \& Moscoso del Prado Martín, 2012). Despite some attempt at 
Amenta, Marelli and Crepaldi, in press. To appear in Journal of Experimental Psychology: Learning, Memory and Cognition.

reconciling this evidence (Davis \& Rastle, 2010; Rastle \& Davis, 2008), it is clear that masked priming data are not completely unequivocal. Thus, it is critical to look for other sources of evidence, in a move towards converging data from different paradigms.

In this respect, it is notable that existing data refer quite exclusively not only to masked priming, but also to isolated word processing. Studying how words like dealer and corner behave within sentences may thus be very important in order to bring a new perspective into the debate. Quite importantly, it would also give us the occasion to see how semantics and form interact during morphological analysis in a condition that is much closer to reading situations in everyday life.

Indeed, the study of word processing in sentence context has been widely used to address morphological processing, with a particular focus on compound words in eye-tracking experiments. The classic marker for morpheme processing in these studies is the effect of constituent frequency: if reading times are influenced by the frequency of the morphemes making up the compound word (and not only by the frequency of the whole compound), this means that the corresponding representations are involved in the processing of the compound. Moreover, eye-tracking provides several dependent variables, which are assumed to reflect progressively deeper levels of processing. This permits to assess the processing stage at which each predictor becomes relevant. Typically, effects on first fixations on a given word are thought to reflect early processing steps, whereas effects on total fixation times (either during first pass or including regressions) are attributed to later stages. Building on this basis, the literature on compound processing in sentence reading has shown that morphemes are important cues for lexical access, and that they are exploited from the very beginning of word processing. Kuperman, Schreuder, Bertram and Baayen (2009), for example, showed that first fixation durations on target compounds are influenced by both first constituent and whole-word frequency. Marelli and Luzzatti (2012) further showed the crucial role of semantic transparency in modulating these effects, that is, early constituent access hinders processing in the 
Amenta, Marelli and Crepaldi, in press. To appear in Journal of Experimental Psychology: Learning, Memory and Cognition.

case of opaque compounds (e.g., honeymoon), but facilitates it in the case of transparent compounds (e.g., snowfall). This evidence shows that semantics may be an early player in compound processing. Interestingly, the methodology and interpretation framework used in eyetracking studies on compounds can be profitably applied to the processing of derived words (e.g., Kuperman, Bertram \& Baayen, 2010), traditionally under the scope of masked priming investigations.

In the present study we follow this path to investigate the role of semantics in the early phases of morphological processing, and in particular the role of stems in processing derived words during sentence reading. In particular, we have exploited a convenient feature of several derived words in Italian, that is, that they can be read in a morphologically transparent or morphologically opaque way according to the sentence context where they belong. For example, the word copertina can refer to a "small blanket". In this case, it is a fully transparent derived word given that blanket is coperta in Italian and -ina is a productive diminutive suffix in Italian, as in matitina, small pencil, scarpina, small shoe, or magliettina, small t-shirt. However, copertina may also mean "cover" (as in books, journals, CD, etc.), which has still something to do with "covering", but not with "blankets" and "smallness". In a sentence like "Era una fredda sera d'inverno, così Lisa si mise sotto una copertina e accese il camino", "It was a cold winter night, so Lisa covered herself with a small blanket and lighted up her fireplace", the transparent meaning of copertina is clearly the only possible one. Conversely, only the opaque meaning is allowed in a sentence like "Aprì il libro e, dopo aver letto la copertina, capì di avere trovato una prima edizione", "She opened the book and, after reading the cover, she realized she had a first edition in her hands". Using different sentence contexts makes exactly the same form either a genuine derivation or a pseudo-derived word. We would thus be able to assess the role of semantics and form in morphological analysis while controlling perfectly for a number of critical factors, such as, e.g., form frequency, word length, and 
Amenta, Marelli and Crepaldi, in press. To appear in Journal of Experimental Psychology: Learning, Memory and Cognition.

affix productivity.

In line with previous studies (e.g., Marelli \& Luzzatti, 2012), we used stem word effects on fixation times as an index of morphological analysis, that is, as an index that the word was segmented and the stem representation accessed during word identification. With this experimental design, it is rather easy to set predictions according to how morphological analysis unfolds in sentence reading. At one extreme, early morphological analysis may just be completely insensitive to semantics, i.e., segmentation operates on both transparent and opaque words, with no role for morpheme meanings (Rastle et al., 2004). In this case, we expect exactly the same effect of stem frequency in transparent and opaque contexts. At the other extreme, segmentation depends on whether morphemes inform whole-word meaning, i.e., morphemes are accessed only in transparent words. If this is the case, we expect a stem frequency effect in transparent contexts, but no effect in opaque contexts. Following the literature on compound processing (Marelli \& Luzzatti, 2012), a third option may be in the game, that is, that segmentation proceeds irrespective of semantic transparency, but morpheme meanings are addressed straight away and thus morpho-orthography facilitates word identification in transparent contexts (because morpheme meanings are consistent with word meaning), but hinders it in "opaque" contexts (because morpheme meanings are inconsistent with word meaning). It is obvious that semantics will become relevant at some point in a sentence comprehension task, but all these predictions refer specifically to early processing stages. Therefore, we expect to observe the described effects when analyzing the durations of first fixations on target words.

\section{Materials and Methods}

\section{Participants}

46 students at the University of Milano-Bicocca were recruited to participate in the study, in 
Amenta, Marelli and Crepaldi, in press. To appear in Journal of Experimental Psychology: Learning, Memory and Cognition.

exchange for course credits. Participants were all skilled readers and native speakers of Italian. They had normal or corrected-to-normal vision, and no history of learning disability or neurological impairment.

\section{Apparatus}

An EyeLink 1000 eye-tracker manufactured by SR Research Ltd. (Mississauga, Ontario, Canada) was employed in order to monitor participants' eye movements during the experiment. A desktop camera sampled the pupil position of the right eye at a frequency of $1000 \mathrm{~Hz}$. The recording was monocular with a $35 \mathrm{~mm}$ lens. System calibration was performed with a 3-point grid at the beginning of the experimental session and was repeated when necessary. Spatial horizontal accuracy was kept in the range of $\pm .30^{\circ}$ of visual angle. Participants' head laid on a chin rest located $60 \mathrm{~cm}$ away from a 120-Hz, 27-inch Acer B291570 monitor. This viewing distance made each degree of visual angle to correspond to $\sim 1.05 \mathrm{~cm}$ of screen space. With Courier New 18 , lowercase font, around 3 characters were subtended by each degree of visual angle.

\section{Materials}

We selected 31 Italian complex words to be used as targets in this experiment. Frequency values for the target words were extracted from the SUBTLEX-IT database (freely available at http://crr.ugent.be/subtlex-it/; Crepaldi, Keuleers, Mandera, \& Brysbaert, 2013). Table 1 describes the characteristics of the target words and their stem morphemes. Each of these words was embedded in two different sentences, one that forced its transparent meaning and one that forced its opaque meaning (see Appendix A). In the opaque context, some stems retained some semantic relationship with the whole-word, as for "copertina", to be interpreted as book cover rather than small blanket, but still referring to something that "covers" (similar to the English case "courteous"). In other cases, the stem meaning was unrelated to the whole-word meaning, as for 
Amenta, Marelli and Crepaldi, in press. To appear in Journal of Experimental Psychology: Learning, Memory and Cognition.

"focaccia", meaning focaccia bread rather than bad seal (similar to the English "corner"). Taken outside their context, the dominant (lexicalized) interpretation would be the opaque one. Sentence

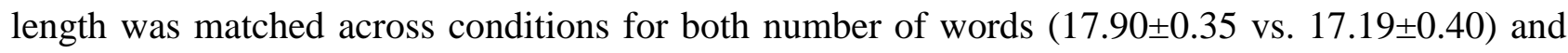
number of characters (105.97 \pm 2.05 vs. $102.16 \pm 2.05)$. To avoid skipping and minimize the impact of word predictability on the collected data, we kept the cloze probability of each critical word as low as possible (lower than 35\%) in all sentences. Moreover, the critical word was always located roughly in the middle of the sentence so as to guarantee optimal viewing conditions to the subjects.

\begin{tabular}{ll}
\hline Variable & Mean (SD) \\
\hline Stem Frequency & $2960(6019)$ \\
Suffix Length & $3.48(0.56)$ \\
Whole-word Frequency & $363(531)$ \\
Whole-word Length & $7.77(1.28)$ \\
\hline
\end{tabular}

Table 1: Characteristics (mean and standard deviation) of the target words. Frequency measures are extracted from SUBTLEX-IT (http://crr.ugent.be/subtlex-it/, corpus size (tokens): 130M).

The assignment of target words to the two conditions was counterbalanced over two lists, so that all targets appeared in both the transparent and opaque conditions, but participants received each target only once. The assignment of the target words to the two lists was counterbalanced across participants.

We added 78 filler sentences, which were in all comparable to the target sentences (e.g., similar length, all including at least one complex word). Thirty-one filler sentences contained derived words ending with the same suffixes as the target words, (i.e., -ina, -etto, -one, etc.); 47 filler sentences contained general suffixed words. Six sentences were also added at the beginning of 
Amenta, Marelli and Crepaldi, in press. To appear in Journal of Experimental Psychology: Learning, Memory and Cognition.

each list in order to have the subjects familiarize with the task, followed by six more trials that were used as warm-up trials and were not eventually analyzed. Each list was then was comprised of 121 trials and took 20 to 25 minutes to go through.

\section{Procedure}

Stimulus presentation and data recording was accomplished via Experiment Builder. Trials began with a fixation point located in the upper-left quarter of a computer screen. This fixation point was exploited to check fixation drift. Each trial followed the fixation point and stayed on screen until participants pressed a button; they were asked to do so when they had fully understood the sentence. No time limit was imposed. $30 \%$ of the sentences were followed by a YES/NO question that ensured text comprehension and kept the subjects focused on the task. A response box was used to collect answers; the YES response button was always controlled by the participants' dominant hand.

\section{Data analysis}

First fixation and gaze durations on the target word were adopted as dependent measures. Gaze duration was defined as the total amount of time spent with the eyes on the critical word before fixating away from it. In order to reduce distribution skewness, first fixation and gaze durations were log-transformed before running the analysis. Mixed-effects models (Baayen, Davidson \& Bates, 2008) were used to analyze the data, as implemented in the lme4 R package (Bates, Maechler, Bolker, \& Walker, 2013). The effects of interest were the type of sentence context (dummy coded with "transparent" as baseline and "opaque" as contrast level), meancentered log-transformed stem frequency, and the interaction between these two variables. Meancentered word length, suffix length (dummy-coded as "short", 3 letters, and "long", 4 or 5 letters) and log-transformed frequency of the derived form were also considered, along with their 
Amenta, Marelli and Crepaldi, in press. To appear in Journal of Experimental Psychology: Learning, Memory and Cognition.

interactions. The effect of fixation position was also included as a covariate in the analysis on first fixation durations. The models included random intercepts for participants and items. Random slopes for all predictors were also evaluated. In the analysis on first fixation durations none contributed significantly to the fit of the models. The analysis on gaze durations benefitted by a random slope of items on context type. Effects were evaluated one by one on the basis of likelihood ratio tests: those whose inclusion did not increase significantly the model goodness-of-fit were removed from the analysis. After having identified the best model with this procedure, atypical outliers were removed employing 2.5 SD of the residual errors as criterion. Statistics of the refitted models are reported. P-values were computed adopting the Satterthwaite approximation for degrees of freedom (Satterthwaite, 1946) as implemented in the lmerTest R package (Kuznetsova, Brockhoff, \& Christensen, 2013).

\section{Results}

Only data about fixations on target words were considered. Fixations that either preceded or followed a blink were excluded from the analyses, as well as datapoints that deviated excessively from a normal distribution. One participant's datapoints were also not considered due to technical problems during data acquisition. The analyzed data set consisted of 1211 valid datapoints.

The average number of fixations on the target was $1.29(\mathrm{SD}=0.53)$, the average first fixation duration was $243 \mathrm{~ms}(\mathrm{SD}=69)$, and the average gaze duration was $301 \mathrm{~ms}(\mathrm{SD}=134) .74 \%$ of the targets required a single fixation for reading, $24 \%$ required two fixations, $2 \%$ required three fixations or more. 
Amenta, Marelli and Crepaldi, in press. To appear in Journal of Experimental Psychology: Learning, Memory and Cognition.

\section{First Fixation Durations}

\begin{tabular}{lcccc}
\hline Fixed Effect & Estimate & Std. Error & $\mathrm{t}$ value & $\mathrm{p}$ \\
\hline Intercept & 5.4441 & 0.0217 & 237.35 & .0001 \\
Context:Opaque & 0.0522 & 0.0196 & 2.49 & .0126 \\
Suffix Length:Long & -0.0147 & 0.0241 & -0.58 & .5611 \\
Whole-word Frequency & -0.0186 & 0.0063 & -2.81 & .0098 \\
Base Frequency & -0.0307 & 0.0146 & -1.99 & .0506 \\
Fixation Position-Linear & 0.0384 & 0.2581 & -0.08 & .9342 \\
Fixation Position-Quadratic & -1.5111 & 0.2415 & -6.54 & .0001 \\
Base Frequency * Context & 0.0476 & 0.0171 & 2.59 & .0095 \\
Base Frequency * Suffix Length & 0.0578 & 0.0191 & 2.42 & .0186 \\
Context * Suffix Length & -0.0098 & 0.0292 & -0.58 & .5616 \\
Base Frequency * Context * Suffix Length -0.0869 & 0.0223 & -3.17 & .0016 \\
\end{tabular}

Table 2: Fixed effects in the final model on first fixation durations. The reported parameters had significant effects and/or significantly improved the model goodness-of-fit.

Table 2 summarizes the results of the analysis on first fixation durations. Most importantly, the interaction between stem frequency and context type was significant, however it was qualified by the modulation of suffix length $(F=10.07, p=.0015)$. The three-way interaction is represented in Figure 1. When the sentence prompted a transparent reading of the target word (copertina, lit., blank-let as in pig-let, meaning "small blanket"), stem frequency had a facilitatory effect on word processing (effect size: $39 \mathrm{~ms}$ ), that is, the larger the frequency of the stem, the shorter the first fixation. However, when the sentence prompted the opaque meaning of the target word (copertina meaning "cover", as in book cover), stem frequency had an inhibitory effect on word processing 
Amenta, Marelli and Crepaldi, in press. To appear in Journal of Experimental Psychology: Learning, Memory and Cognition.

(effect size: $23 \mathrm{~ms}$ ), that is, the larger the frequency of the stem, the longer the first fixation ${ }^{1}$. This effect, however, is clear for words with short suffixes (left panel of Figure 1), but not for word with long suffixes (right panel of the same figure). Moreover, a main effect of the frequency of the derived form ${ }^{2}$ also emerged: the higher the frequency, the shorter the associated first fixation durations. Finally, a significant non-linear (inverse-U shaped) effect of fixation position was found, indicating that the closer the fixations are to the word-center, the longer they become (the wellknown Inverted Optimal Viewing Position effect; e.g., Vitu, Lanceline, \& Marrier d’Unienville, 2007).

1 The same pattern of results is also produced when using log-transformed context-diversity $(\mathrm{CD}$; the number of context in which a word appears) in place of log-frequency. This result is not surprising given the high correlation of CD and frequency in our set (.97).

2 Frequency was also measured separately for opaque and transparent meanings of the same word. Given that the opaque meaning was dominant, we wanted to make sure that the relative familiarity with this meaning over the other did not affect the present results. We collected ratings of meaning-specific subjective frequency from a sample of 30 subjects. These new subjective frequency estimates were inserted into the model in place of whole-word frequency, and turned out to be a significant predictor of fixation durations $(b=0.0225 ; \mathrm{t}=-2.05 ; p=.0410)$. Most importantly, the interaction of interest was significant also in this new model ( $\mathrm{F}=10.99 ; p=.0009)$, and reflected the same pattern of results. The results held also when we distributed overall whole-word frequency to transparent and opaque meanings proportionally to the ratings, in order to make sure that the predictor took into account the actual frequency of the individual word acceptation. 
Amenta, Marelli and Crepaldi, in press. To appear in Journal of Experimental Psychology: Learning, Memory and Cognition.
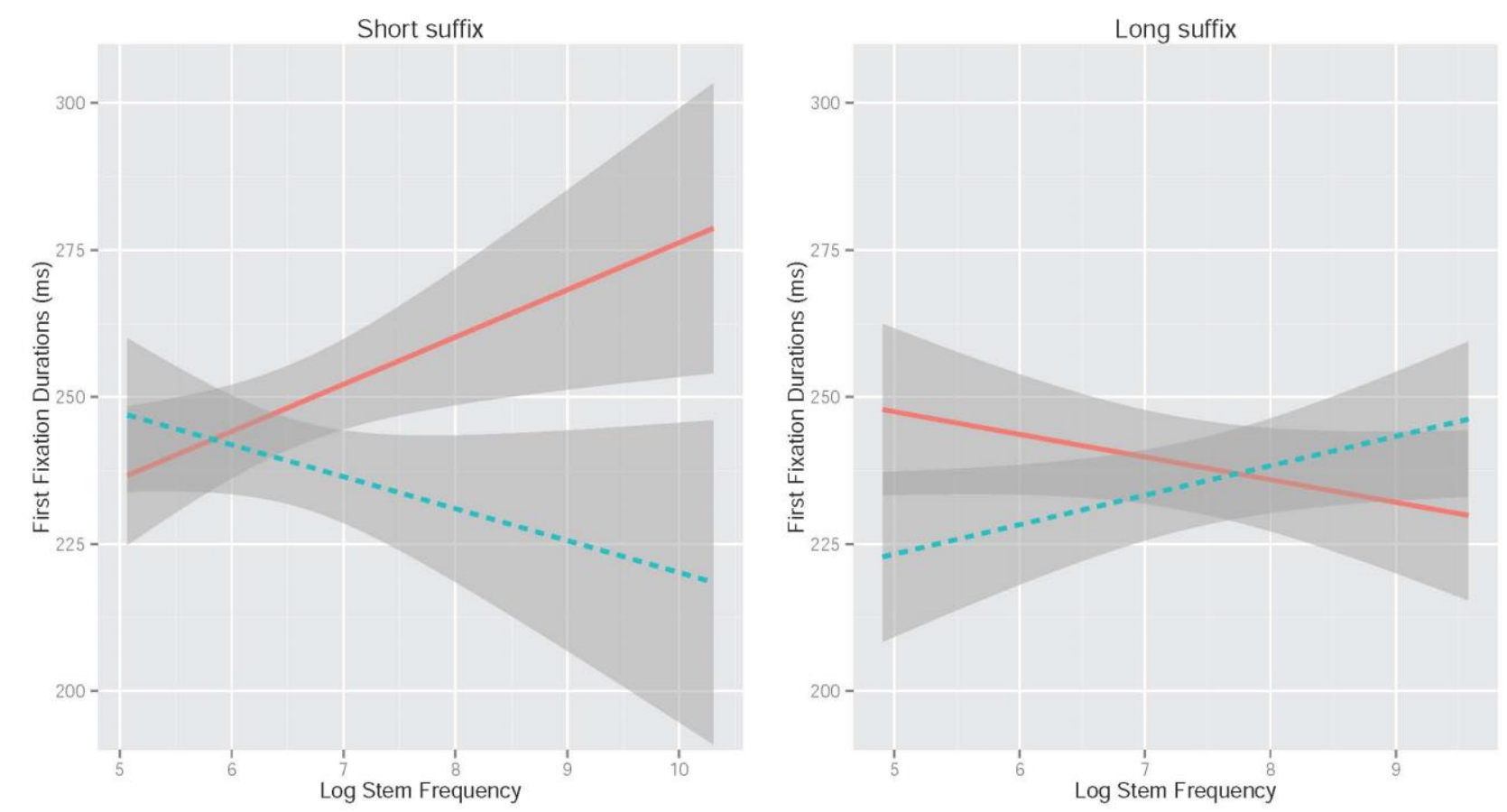

Figure 1: Three-way interaction between context type and stem frequency and suffix length on first fixation durations. Lefthand panel represents results for words with short suffixes, while the righthand panel represents results for words with long suffixes. The blue dotted line represents the effect in transparent contexts; the red solid line represents the effect in opaque contexts.

\section{Gaze Durations}

A main effect of whole-word frequency was observed $(b=-0.026 ; \mathrm{t}=-2.63 ; p=.0137)$ : the higher the frequency of the derived form, the shorter the gaze durations. The crucial aspect of these results, however, is the absence of any sentence context modulation of stem word frequency effects, thus suggesting that this critical interaction is specific to early measures, those that most likely reflect pre-lexical and early lexical processing.

\section{Discussion}

The long-standing debate around how early semantics inform morphological decomposition has mostly been addressed in masked priming studies with isolated words. Here we add a new 
Amenta, Marelli and Crepaldi, in press. To appear in Journal of Experimental Psychology: Learning, Memory and Cognition.

perspective to this debate by studying derived words during sentence reading for comprehension, which brings us closer to real-life reading situations. In particular, we studied how first fixations (taken as a reflection of early stages of processing) on derived words are influenced by the frequency of the stem word; this effect is taken as an index of the involvement of stem representations in word processing. Importantly, we did so by manipulating sentence context so that exactly the same target words could be read as either transparent or opaque derivations. This allowed a within-target design, which implies superior control over several possible confounding variables (e.g., suffix length, family size and productivity).

Results were clear-cut in showing an effect of stem word frequency in both opaque-biased and transparent-biased sentences, thus indicating that the target word was segmented in both the opaque and the transparent contexts. Hence, also in natural sentence reading word decomposition proceeds irrespectively of whether (pseudo-)stems contribute to word meaning (morphoorthographic segmentation). However, stem word frequency had opposite effects in the two types of contexts, namely, it facilitated processing in transparent words while hindering it in opaque words. Because this interaction was apparent in first fixation durations and it is clearly a morpho-semantic effect in nature, this strongly indicates an early activation of morpheme meanings. In other words, the semantic representations of the stem morphemes are accessed as early as the word is first encountered. As a consequence, during the combinatorial process that allows the comprehension of the whole-word meaning, if the meaning of the stem is compatible with that of the whole-word (as in the case of the "transparent" contexts), then its early access facilitates the processing of the whole-word semantics. In contrast, when the meaning of the stem is unrelated to the meaning of the whole derived form (as in the case of the "opaque" contexts), its early access will trigger a combinatorial process destined to failure, eventually hindering the process. In other words, the ease of access to the stem meaning (indexed by the stem frequency effect) has opposite effects on word 
Amenta, Marelli and Crepaldi, in press. To appear in Journal of Experimental Psychology: Learning, Memory and Cognition.

processing that depend on the feasibility of the consequent morpheme combination (see Marelli \& Luzzatti, 2012).

This pattern of results does not support either of the two traditional accounts of early morphological processing in word recognition, namely the form-with-meaning account (e.g. Feldman et al., 2012) or the form-first account (e.g. Crepaldi et al., 2010), as seen in the Introduction. Rather, it shows that morphological processing at early level encompasses aspects from both accounts: segmentation is indeed initially determined by form, that is, both transparent and opaque words are broken down into their morphemes. However, the morphological representations resulting from the segmentation are semantically connoted, in fact the identification of a (pseudo-)stem facilitates word processing in transparent contexts, and inhibits it in opaque contexts. Of course, we cannot be completely sure that what is called "early stages" in masked priming experiments is exactly the same as the "early stages" revealed by the analysis of first fixation (vs. gaze) duration reported here. Also, it is conceivable (although not likely, in our view) that morpho-orthographic segmentation and semantic activation happened serially (as form-first models would predict), but both before the end of the first fixation. Still, these data do highlight some inconsistency between sentence reading and models of single word identification that open interesting issues for new research.

Another interesting implication of our results concerns the way semantic transparency should be conceived in sentence reading. Semantic transparency is typically described as the similarity between the meaning of a stem and the meaning of a derived word as a whole. In this experiment, however, the lexicalized, whole-word meaning is always the opaque one. The (dominant) stem meaning is never coherent with the (dominant) whole word meaning, if the latter is considered outside context. It is easy to see, then, that this perspective fails to explain the context modulation of the stem frequency effect that we see in our data - since the dominant meaning of 
Amenta, Marelli and Crepaldi, in press. To appear in Journal of Experimental Psychology: Learning, Memory and Cognition.

the derived words is always an opaque one, stem frequency should always have an inhibitory effect on processing time. What seems to be relevant, instead, is how the meaning of the combination of stem and affix fits with the constraints created by the sentence context. In other words, the semantic transparency of the derived form is revealed, in our case, by the plausibility of the meaning combination of stem and affix in light of the preceding sentence context. When the context is in line with the meaning emerging from the combination of the stem and the affix, stem frequency is facilitatory. When the context is not in line with the meaning of stem and affix combination (that is, the context is consistent with the lexicalized meaning of the derived word) stem frequency is inhibitory. Effectively, semantic transparency emerges in our data as the relationship between the sentence context and the combination of stem and affix, rather than between the whole word and the stem.

The combinatorial account of early semantic processing of complex words proposed here predicts that two elements (stem and affix) are used to compute the meaning of the complex form; in other words, the semantic contribution of the stem should be crucially qualified by the cooccurrent activation of the affix. The effect of suffix length clearly supports this prediction, indicating that the stem frequency effects are most evident for words with short suffixes. In our data, first fixation position fell on average two letters on the left of the center of the derived word, that is, deeply into the word stem and quite far from the suffix. Under these conditions, longer suffixes are likely to fall far away from the fixation point, where visual acuity is diminished and crowding is strong (Bouma, 1973). This would hinder the processing of the affix-associated morphological and semantic information ${ }^{3}$, and the consequent combinatorial procedure. Short

3 The hypothesis that morphological and semantic information is not fully available at the first fixation for long suffixes is supported by an analysis on the probability of additional fixations on the word. Long-suffix words were more likely to elicit additional fixations than short-suffix words $(\mathrm{z}=2.19, p<.0285)$, indicating that further visual uptake was more often needed for words embedding long suffixes. 
Amenta, Marelli and Crepaldi, in press. To appear in Journal of Experimental Psychology: Learning, Memory and Cognition.

suffixes, on the other hand, would be more likely to be fully processed during the first fixation, thus allowing the combinatorial procedure.

These results also allow to update previous data showing that morphological segmentation does not happen for opaque words in a masked priming paradigm where participants undertake a semantic task, rather than lexical decision (Marelli, Amenta, Morone \& Crepaldi, 2013). The present results allow to extend this knowledge by clarifying that neither it is semantic processing per se that determines a lack of morpho-orthographic segmentation (clearly, the task used in this experiment does require comprehension, and still we have clear evidence for morphological analysis of opaque words), nor it is the morpho-orthographic effect a mere by-product of strategic behaviors strictly associated to the co-presence of a masked priming paradigm and a lexical decision task, as one my conclude from the original work from Marelli et al. (2013). In this respect, it is worth noting that the present evidence is found under ecological conditions and extremely limited experimental manipulations. Therefore, one possible explanation of why we were able to report a morpho-orthographic effect in a semantic task might reside in the paradigm we adopted. In fact, in masked priming paradigms, the processing of the morphologically complex word (typically, the prime) is not observed directly, but only deduced through its outcome on the processing of the stem (typically, the target). In contrast, in the present study we measured the processing of derived words directly, thus providing unmediated evidence of involvement of morphemes in the identification and comprehension of complex words of the full form.

Finally, another interesting feature of these data is that they nicely suit results obtained on compound word processing using a similar paradigm. As also illustrated in the Introduction, Marelli and Luzzatti (2012) found constituent frequency effects that were facilitatory in transparent compounds and inhibitory in opaque compounds already on first fixation durations, which mirrors what we have found in the present experiment with derived words. So, both derived and compound 
Amenta, Marelli and Crepaldi, in press. To appear in Journal of Experimental Psychology: Learning, Memory and Cognition.

words, when studied in the context of sentence reading, indicate (i) early morphological decomposition independent of semantic transparency, and (ii) early access to the semantic representations of the individual morphemes. This ties together two lines of research (compound processing and derived word processing) that typically run in parallel with little contact in spite of being clearly closely related at the theoretical level.

\section{References}

Algeo, J. (1991). Fifty years among new words: A dictionary of neologisms. Cambridge: Cambridge University Press.

Baayen, R. H., Davidson, D. J., \& Bates, D. M. (2008). Mixed-effects modeling with crossed random effects for subjects and items. Journal of Memory and Language, 59(4), 390-412.

Bates, D., Maechler, M., Bolker, B., \& Walker, S. (2013). lme4: Linear mixed-effects models using Eigen and S4. $\mathrm{R}$ package version 1.0-5. Retrieved from http://CRAN.Rproject.org/package=lme4Bradley, D.C. (1979). Lexical representation of derivational relation. In M. Aronoff \& M. L. Kean (Eds.), Juncture (pp. 37-55). Cambridge, MA: MIT Press.

Bouma, H. (1973). Visual interference in the parafoveal recognition of initial and final letters of words. Vision Research, 13, 767-782.

Crepaldi, D., Keuleers, E., Mandera, P., \& Brysbaert, M. (2013). SUBTLEX-IT. Retrieved from http://crr.ugent.be/subtlex-it/

Crepaldi, D., Rastle, K., Coltheart, M., \& Nickels, L. (2010). 'Fell' primes 'fall', but does 'bell'prime 'ball'? Masked priming with irregularly-inflected primes. Journal of Memory and Language, 63(1), 83-99. 
Amenta, Marelli and Crepaldi, in press. To appear in Journal of Experimental Psychology: Learning, Memory and Cognition.

Davis, M. H., \& Rastle, K. (2010). Form and meaning in early morphological processing: Comment on Feldman, O’Connor, and Moscoso del Prado Martín (2009). Psychonomic Bulletin \& Review, 17(5), 749-755.

Diependaele, K., Sandra, D., \& Grainger, J. (2005). Masked cross-modal morphological priming: Unravelling morpho-orthographic and morpho-semantic influences in early word recognition. Language and Cognitive Processes, 20(1-2), 75-114.

Eyelink 1000 [apparatus and software]. (2010). Mississauga, Canada: SR Research.

Feldman, L. B., Kostić, A., Gvozdenović, V., O’Connor, P. A., \& Moscoso del Prado Martín, F. (2012). Early Morpho-semantic processing in Serbian: A violation of form-then-meaning accounts of word recognition. Psychonomic Bulletin \& Review, 19(4), 668-676.

Feldman, L. B., O’Connor, P. A., \& del Prado Martín, F. M. (2009). Early morphological processing is morphosemantic and not simply morpho-orthographic: A violation of formthen-meaning accounts of word recognition. Psychonomic Bulletin \& Review, 16(4), 684691.

Kuperman, V., Bertram, R., \& Baayen, R. H. (2010). Processing trade-offs in the reading of Dutch derived words. Journal of Memory and Language, 62(2), 83-97.

Kuperman, V., Schreuder, R., Bertram, R., \& Baayen, R. H. (2009). Reading polymorphemic Dutch compounds: toward a multiple route model of lexical processing. Journal of Experimental Psychology: Human Perception and Performance, 35(3), 876.

Kuznetsova, A., Brockhoff, P. B., \& Christensen, R. H. B. (2013). lmerTest: Tests for random and fixed effects for linear mixed effect models (lmer objects of lme4 package). R package version 2.0-3. Retrieved from http://CRAN.R-project.org/package=lmerTest

Longtin, C. M., Segui, J., \& Halle, P. A. (2003). Morphological priming without morphological relationship. Language and Cognitive Processes, 18(3), 313-334. 
Amenta, Marelli and Crepaldi, in press. To appear in Journal of Experimental Psychology: Learning, Memory and Cognition.

Marelli, M., \& Luzzatti, C. (2012). Frequency effects in the processing of Italian nominal compounds: Modulation of headedness and semantic transparency. Journal of Memory and Language, 66(4), 644-664.

Marelli, M., Amenta, S., Morone, E. A., \& Crepaldi, D. (2013). Meaning is in the beholder's eye: Morpho-semantic effects in masked priming. Psychonomic Bulletin \& Review, 20(3), 534541.

Rastle, K., \& Davis, M. H. (2008). Morphological decomposition based on the analysis of orthography. Language and Cognitive Processes, 23(7-8), 942-971.

Rastle, K., Davis, M. H., \& New, B. (2004). The broth in my brother's brothel: Morphoorthographic segmentation in visual word recognition. Psychonomic Bulletin \& Review, 11(6), 1090-1098.

Satterthwaite, F. E. (1946). Of variance components. Biometrics, 2(6), 110-114.

Taft, M., \& Forster, K. I. (1975). Lexical storage and retrieval of prefixed words. Journal of Verbal Learning and Verbal Behavior, 14(6), 638-647.

Vitu, F., Lancelin, D., \& Marrier d'Unienville, V. (2007). A perceptual-economy account for the inverted-optimal viewing position effect. Journal of Experimental Psychology: Human Perception and Performance, 33(5), 1220-1249. 
Amenta, Marelli and Crepaldi, in press. To appear in Journal of Experimental Psychology: Learning, Memory and Cognition.

\section{APPENDIX A - Items used in this Experiment}

The table contains all the items used in the Experiment. Critical words are highlighted in bold. Each sentence is followed by English glosses.

Context Sentence

Glosses

Transparent Tra gli scaffali della vecchia biblioteca, Irene trovò un libretto di poesie che aveva tanto amato da giovane.

On the shelves of the old library, Irene found a small book of poems she had so loved as a young woman.

Opaque Per prepararsi alla prima dell'opera a La Scala, Luca andò a comprare il libretto de Il don Giovanni. To get ready for the premiere of the opera at La Scala, Luca went to buy the libretto of Il Don Giovanni.

Transparent Gaia scelse un abito da sposa decorato con del grazioso pizzetto sulla scollatura e lustrini sulle spalline. Gaia chose a wedding dress decorated with a lovely lace neckline and sequined straps.

Opaque Dal barbiere, Carlo chiese di regolare il pizzetto e tagliare i capelli.

At the barber-shop, Carlo asked (the barber) to trim his goatee and to cut his hair.

Luca pensava di lavorare per un quotidiano serio, ma capì che era un giornaletto da poco dopo aver parlato col Transparent direttore.

Luca thought he was working for a serious newspaper, but after talking to the editor-in-chief, he realized it was just a sloppy newspaper.

Opaque Il nonno portò Marco in fumetteria a comprare il suo giornaletto illustrato preferito, come ogni lunedì.

The grandfather took Marco at a comic books shop to buy his favorite illustrated comic-book, as every Monday.

Transparent Era una fredda sera d'inverno, così Lisa accese il camino, si mise sotto la copertina sul divano e guardò un film. It was a cold winter evening, so Lisa turned on the fireplace, she placed herself under the small blanket on the couch and watched a movie.

Opaque Aprì il libro e, dopo aver letto la data nella quarta di copertina, capì di aver trovato una prima edizione. He opened the book and, after reading the date on the back cover, he realized he had found a first edition.

Transparent Il paesaggio era incantevole: una casetta sulla collina e soffici nuvole di fumetto bianco che uscivano dal caminetto. The scenery was lovely: a little house on the hill and fluffy white clouds of light smoke coming out of the chimney.

Opaque Da grande fan di Superman, comprò il nuovo numero del fumetto e dedicò il pomeriggio alla lettura. As a great fan of Superman, he bought the new issue of the comic-book and spent the afternoon reading it.

Transparent Sistemò sul comodino accanto al letto la piccola lampadina ad olio per creare un'atmosfera di luce diffusa, She placed the small oil lamp on the nightstand, to create an atmosphere of diffused light.

Opaque Lucia accese la luce, ma si rese conto che la lampadina, acquistata il giorno prima, non funzionava. 
Amenta, Marelli and Crepaldi, in press. To appear in Journal of Experimental Psychology: Learning, Memory and Cognition.

Lucia turned on the light, but she realized that the light bulb, bought the day before, was broken.

Transparent La campagna era tranquilla, con lunghi campi di grano e un vecchio mulinello che faceva girare lente le sue pale.

The countryside was quiet, with long wheat fields and an old little mill that turned his blades slowly.

Opaque Il fiume scorreva rapido e si formò un pericoloso mulinello tra le acque, che mise in difficoltà molti bagnanti.

The river was flowing fast and formed a dangerous whirlpool in the waters, which put many swimmers in difficulty.

Transparent Avvistando la preda dall'alto, un grosso e affamato aquilone si scagliò in picchiata su di essa.

Spotting the prey from above, a large and hungry eagle dived on it.

Opaque Inseguendo una leggera brezza, il bimbo giocava a far volare l'aquilone sempre più in alto.

Chasing a light breeze, the child was flying the kite higher and higher.

Transparent Per completare il suo collage, il bimbo chiese all'amico la collina stick e qualche pezzetto di carta colorata.

To complete his collage, the child asked his friend (to lend to him) the small glue-stick and a few pieces of colored paper.

Opaque In lontananza Maria poteva scorgere la collina su cui si trovava la vecchia casa di famiglia.

Maria could see in the distance the hill on which stood the old family home.

Transparent Si sentì un intenso odore di gas e subito dopo un improvviso bottone interruppe il silenzio della notte.

There was a strong smell of gas and immediately after that a sudden huge thud broke the silence of the night.

Opaque Provandosi la camicia, Mauro si accorse di aver perso il bottone del polsino.

Trying on the shirt, Mauro realized he had lost the cuff button.

Transparent Tornò dalla passeggiata nel bosco portando con sé un mazzolino di fioretti raccolti in una radura.

He came back from the walk in the woods, carrying a bunch of little flowers picked up in a clearing.

Opaque Durante il periodo della Quaresima Luca fece due fioretti: non dire bugie e non rompere i giochi del fratello.

During the Lent Luca decided to make two pledges: not to tell lies, and not to break the his brother's toys.

Transparent Dalla camera il bimbo osservava la tempesta quando un lampone rischiarò il cielo, seguito da un fragoroso tuono.

From his room (window) the child was watching the storm when a huge lightning illuminated the sky, followed by a loud thunder.

Opaque Era ghiotta di frutti di bosco, ma il suo preferito era il lampone, seguito poi dalle more e dal mirtillo.

He was fond of berries, but his favorite was the raspberry, followed by blackberries and blueberries.

Transparent Gli animali del fattore avevano vinto molti premi alla fiera, ma il gallone dell'avversario aveva vinto il primo.

The farmer's pets had won many prizes at the fair, but the opponent's big rooster had won the first prize.

Opaque

Prima di attraversare il deserto, per non rimanere a secco, prese un gallone di benzina insieme a tre bottiglie d'acqua.

Before crossing the desert, not to remain without fuel, he picked up a gallon of gasoline along with three bottles of water. 
Amenta, Marelli and Crepaldi, in press. To appear in Journal of Experimental Psychology: Learning, Memory and Cognition.

\footnotetext{
L'addestratore sgridò il leone marino dicendo: "Sei proprio una cattiva focaccia, non devi rubare il pesce ai Transparent cuccioli!"

The trainer rebuked the sea lion saying: "You're just a bad seal, you must not steal the fish from the puppies!"

Opaque In vacanza in Liguria, ne approfittò per pranzare con una bella fetta di focaccia di Recco con tanto formaggio.

On holiday in Liguria, she took the opportunity to have lunch with a slice of focaccia cake of Recco topped with a lot of cheese.
}

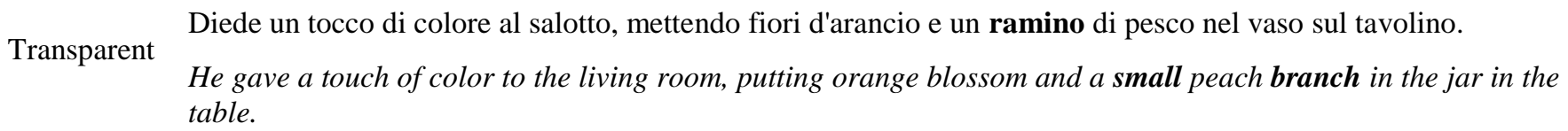

Opaque Prima di insegnare a Sergio a giocare a scopa, gli spiegò le regole del ramino, che era un gioco molto più facile. Before teaching Sergio how to play straight, he explained to him the rules of rummy, a game that was much easier.

Transparent La leggenda narrava di un eroe che sconfisse il perfido magone e riportò la quiete nel piccolo villaggio.

The legend told of a hero who defeated the great evil wizard and brought the peace back to the small village.

Opaque La vacanza era quasi finita e a Eva veniva il magone al solo pensiero che avrebbe dovuto salutare i suoi amici.

The holiday was almost over and Eva was choked up at the thought that she should greet his friends.

Transparent Per attraversare lo stretto tra gli isolotti bisogna prendere una navetta a vapore che parte dal porto del paese.

To cross the strait between the islands you have to take a small steam boat that leaves from the village harbour.

Opaque Per raggiungere il terminal doveva prendere la navetta gratuita che fermava nel parcheggio vicino l'aeroporto.

To reach the terminal she had to take the free shuttle bus that stopped in the parking lot near the airport.

Transparent Sono stanca di lavorare, potrei fare un girino in centro e magari un po' di shopping.

I'm tired of working, I could make a short stroll in the center and maybe a do little shopping .

Opaque Apprese con disgusto che il piccolo della rana si chiamava girino ed era una creaturina nera e viscida.

He learned with disgust that the little frog is called a tadpole and it was a black and slimy creature.

Transparent Durante l'incendio prese l'estintore e lo usò, ma il violento gettone di schiuma che ne scaturì lo fece cadere.

During the fire, he took the fire extinguisher and used it, but the violent big spray of foam that ensued caused him to fall.

Opaque

Una volta, per telefonare quando si era fuori casa, bisognava inserire il gettone nella cabina telefonica e digitare.

Once (in the past), when you had to make a phone call while out of the house, you had to insert a coin in the phone booth and type the number.

Transparent Il mio povero bimbo malato ha proprio una brutta tossina, meglio andare a comprare dello sciroppo.

My poor sick baby has a really bad light cough, better go buy the syrup.

Opaque Era stato chiamato dal centro di microbiologia per isolare la tossina responsabile della moria dei pesci.

He had been called from the center of microbiology to isolate the toxin responsible for the die-off of fish. 
Amenta, Marelli and Crepaldi, in press. To appear in Journal of Experimental Psychology: Learning, Memory and Cognition.

\footnotetext{
Per i gavettoni di ferragosto, Paolo prese un secchione, lo riempì d'acqua e lo tirò addosso al fratellino.

Transparent

For the traditional splash of cold water of August, Paolo took a big bucket filled it with water and emptied it onto
} his little brother.

Opaque Aveva i voti più alti di tutti, ma era stanco di essere considerato un secchione, così smise di studiare.

He had the highest grades of all, but he was tired of being considered a nerd, so he stopped studying.

Transparent Ho bisogno di un consiglio per la tesi; se mi dessi solo un piccolissimo spuntino sono sicura che finirei subito.

I need some advice for my thesis; if only you could give me a very small prompt I'm sure it would end soon.

Opaque Non avendo molto tempo in pausa pranzo, fece un veloce spuntino e tornò subito al lavoro.

Not having much time on her lunch break, she took a quick bite and went back to work immediately.

Transparent Si accorse della slitta di Babbo Natale quando sentì il suono delle campanelle giungere da lontano nella neve.

He was aware of Santa's sleigh when he heard the sound of little bells coming from far away in the snow.

Opaque Raccolse un mazzolino di campanelle e margherite e li mise in un vasetto in salotto.

He picked up a bunch of trumpet-flowers and daisies and put them in a jar in the living room.

Transparent Al mercato comprò una cassetta di fragole e una di ciliegie.

At the market, he bought a small crate of strawberries and one of cherries.

Opaque Accese il videoregistratore e inserì la cassetta per vedere un vecchio film in bianco e nero.

He turned on the video recorder and inserted the tape to see an old film in black and white.

Transparent All'indomani di un sabato piovoso fu facile tornare dai boschi con un bel cestello pieno di ottimi funghi.

In the aftermath of a rainy Saturday it was easy to come back from the woods with a fine small basket full of excellent mushrooms.

Opaque La centrifuga della lavatrice era violenta, si poteva sentire il rumore del cestello che girava all'impazzata.

The spin of the washing machine was so violent you could hear the sound of the drum that spun wildly.

Transparent Terminò il rammendo facendo un nodino e tagliando il filo: ora il vestito era pronto per essere messo.

He finished mending by making a little knot and then cut the thread: the dress was now ready to be put on.

Opaque Alla grigliata in giardino mangiò moltissimo: tre costine, un nodino di maiale e due salamelle.

At the barbecue in the garden he ate a lot: three ribs, a pork cutlet and two sausages.

Transparent Preparò la gabbietta per il suo coniglietto adagiando della paglietta e della segatura sul fondo.

He prepared the cage for her pet rabbit by placing some straw(-let) and sawdust on the bottom.

Opaque Per pulire la griglia incrostata aveva bisogno di una robusta paglietta di metallo e tantissimo disincrostante.

To clean the encrusted grill, he needed a robust steel wool and a lot of descaling.

Transparent Per non sporcarsi le mani con l'inchiostro, tappò la penna col suo cappuccino e se la mise in tasca In order not to get her hands dirty with ink, she covered her pen with its little cap and put it in her pocket. 
Amenta, Marelli and Crepaldi, in press. To appear in Journal of Experimental Psychology: Learning, Memory and Cognition.

Opaque Come ogni mattina, Giulia ordinò al bar un cappuccino e una brioches, prima di andare al lavoro.

Like every morning at the bar, Julia ordered a cappuccino and a croissant before heading to work.

Transparent Per la finale dei mondiali di calcio aveva invitato alcuni amici e fecero un tifone da stadio per la nazionale.

For the final of the World Cup he invited some friends over and they did a huge cheer (they cheered loudly) like they were in a stadium for the national team.

Opaque Una tempesta era appena passata e già la radio annunciava che un violentissimo tifone sarebbe arrivato a breve. A storm had just passed and already the radio was announcing that a violent typhoon would come soon.

Transparent Prepararono il pranzo al sacco mettendo delle fette di salame in un panetto e lo avvolsero nella carta stagnola. They packed lunch by putting slices of salami in a small loaf of bread and wrapped it in aluminum foil.

Opaque Prima di iniziare a preparare la torta, mise un panetto di burro ad ammorbidirsi a bagnomaria.

Before starting to prepare the cake, she put a stick of butter to soften in a water bath.

Transparent

Per fare uno scherzo alla madre, il teppista sparò una bombetta puzzolente che impestò la cucina per tre giorni. To make a practical joke to his mother, the little rascal dropped a small stink bomb that flood the kitchen for three days.

Opaque Passeggiando per Londra, è facile incrociare uomini con ombrello e bombetta che si muovono da un ufficio all'altro. Walking around London, it is easy to meet men with umbrella and bowler who move from one office to another. 